\title{
A Case of Spontaneous Pneumomediastinum Following Ecstasy and Marijuana Use
}

\author{
Mishouri Paul ${ }^{1}$, Prodip Paul ${ }^{2}$, Dipon Dey ${ }^{3}$, Amit Bhardwaj ${ }^{2}$, Koushik Paul ${ }^{4}$ \\ 1. Medicine, Interfaith Medical Center, New York City, USA 2. Internal Medicine, Geisinger Community Medical Center, \\ Scranton, USA 3. Epidemiology and Public Health, ZWH Medical Care PC, Queens, USA 4. Clinical Pathology, \\ Community Based Medical College Hospital, Mymensingh, BGD
}

Corresponding author: Mishouri Paul, paul.mishouri@gmail.com

\begin{abstract}
Spontaneous pneumomediastinum (SPM) is a benign and self-limiting condition more commonly seen in young adults. Radiology imaging of the chest, including X-ray or CT scan, is the gold standard for diagnosis. Ecstasy, also known as 3,4-methylenedioxymethamphetamine (MDMA) is a synthetic amphetamine derivative widely abused for an increased sense of well-being and euphoria. Marijuana is also abused for recreational purposes. SPM has been reported after both Ecstasy and marijuana use. SPM after these illicit drugs abuse usually has a benign and self-limiting course with supportive management. However, it is always important to rule out serious associated conditions like esophageal perforation. Here, we present a 22-year-old male who developed SPM after Ecstasy ingestion and marijuana inhalation.
\end{abstract}

Review began 06/08/2021 Review ended 06/12/2021 Published 06/23/2021

(๑) Copyright 2021 Paul et al. This is an open access article distributed under the terms of the Creative Commons Attribution License CC-BY 4.0., which permits unrestricted use, distribution, and reproduction in any medium, provided the original author and source are credited.
Categories: Cardiac/Thoracic/Vascular Surgery, Gastroenterology, Pulmonology

Keywords: pneumomediastinum, subcutaneous emphysema, ecstasy, marijuana, boerhaave's syndrome

\section{Introduction}

Spontaneous pneumomediastinum (SPM) is a rare condition with an incidence estimated between $0.001 \%$ and $0.01 \%$ in adult patients. It is commonly seen in young males with chest pain, shortness of breath, and subcutaneous emphysema [1]. Exacerbation of asthma, tobacco, corticosteroids, vomiting, cough, physical exercise, labor, and abuse of recreational drugs such as cocaine, marijuana, and Ecstasy have been reported to trigger pneumomediastinum [2,3]. Excessive positive airway pressure causes overinflation and rupture of alveoli [2]. Escape of air through the perivascular alveoli into the mediastinum along a pressure gradient, and thereafter to the fascial planes of the neck is responsible for SPM [4].

Marijuana is the most commonly used psychotropic drug in the United States, after alcohol. In 2018, more than 11.8 million young adults reported using marijuana in the past year. A case report has been published on how performing Valsalva maneuvers during marijuana smoking causes pneumomediastinum [5]. SPM in marijuana users is believed to result from either tearing the esophagus due to cyclic vomiting or microperforation of the esophagus [6] or from barotrauma during breathing maneuvers [5,7].

Ecstasy is an illegal street drug widely abused by adolescents and young adults for recreational purposes $[2,8]$. The active ingredient of Ecstasy is 3,4-methylenedioxymethamphetamine (MDMA). It induces a state of increased alertness and euphoria secondary to its stimulant activity in the central nervous system. Due to its chemical similarity related to the psychostimulant methamphetamine and the hallucinogen mescaline, the drug produces stimulating and mild hallucinogenic effects [9]. Both Ecstasy ingestion and inhalation are associated with SPM $[2,10]$. Although there are no reports of mortality directly related to Ecstasy-associated SPM, ecstasy ingestion may lead to significant and potentially life-threatening complications including hyperthermia, cardiac arrhythmias, seizures, fulminant hepatic toxicity, and acute renal failure [2]. Therefore, it is important to monitor the patient during the brief period of hospitalization.

Once more, fatal condition of esophageal perforation is ruled out, Ecstasy and marijuana-related pneumomediastinum are managed with conservative measures [4,7]. Here, we present a 22 -year-old male who developed SPM with subcutaneous emphysema after smoking marijuana and Ecstasy ingestion.

\section{Case Presentation}

A 22-year-old male with a past medical history of bronchial asthma presented to the emergency department with complaints of sudden onset neck and chest pain. The patient stated that around midnight which was about 20 hours prior to arrival to ED, he ingested ecstasy and smoked marijuana. The patient was awake and active the whole night and he was doing well until morning. Then he went to take a shower when he had an episode of the projectile and non-bloody vomiting. The patient then noticed some changes in his voice. The patient had another episode of projectile vomiting. Since then, the patient complained of pain in the neck and chest. The patient denies any shortness of breath, cough, nausea, or any further episodes of vomiting. The patient also denies any fever or chills. The patient had a history of asthma that had been well controlled. 


\section{Cureus}

The patient reported marijuana smoking at least once a week for the past several years. On examination, the patient was in no acute distress, other than tachycardia hemodynamically stable, saturating well on room air. On palpitation, crepitus was noted over the lower part of the neck and upper chest wall. Chest x-ray shows pneumomediastinum and subcutaneous emphysema (Figure 1).

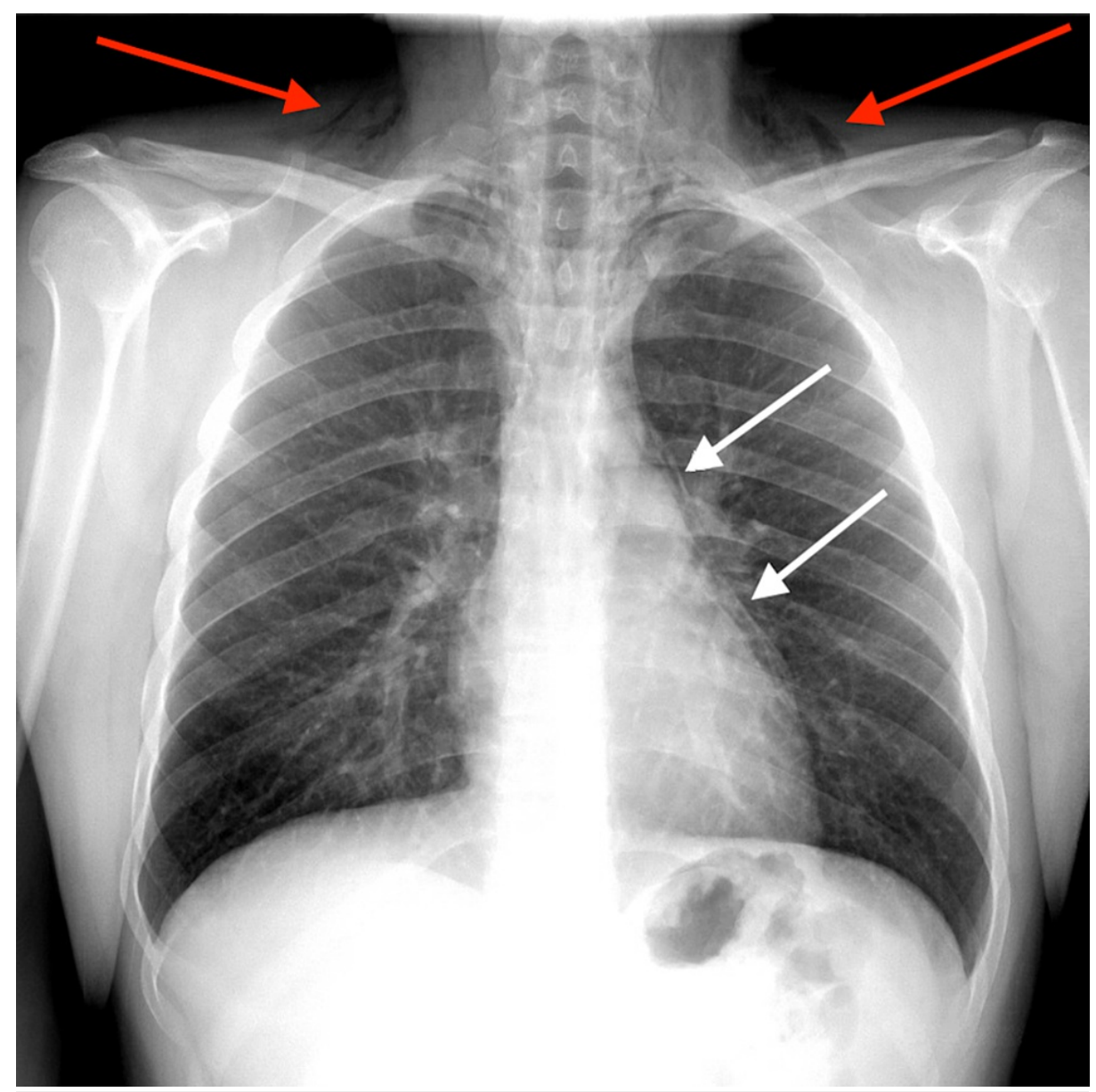

FIGURE 1: Chest x-ray showing subcutaneous emphysema (red arrows) and pneumomediastinum (white arrows)

CT scan of the neck with intravenous contrast showed extensive gas involving the neck. Involved spaces included submandibular space, sublingual space, perivertebral space, and retropharyngeal space (Figure 2). The cardiothoracic surgeon evaluated the patient. The patient also had a CT scan of the chest with oral contrast, and it showed extensive pneumomediastinum (Figure 3). Esophagogram was performed as well to rule out Boerhaave's syndrome. Both CT scan of the chest with oral contrast and esophagogram did not reveal any esophageal leak. 


\section{Cureus}

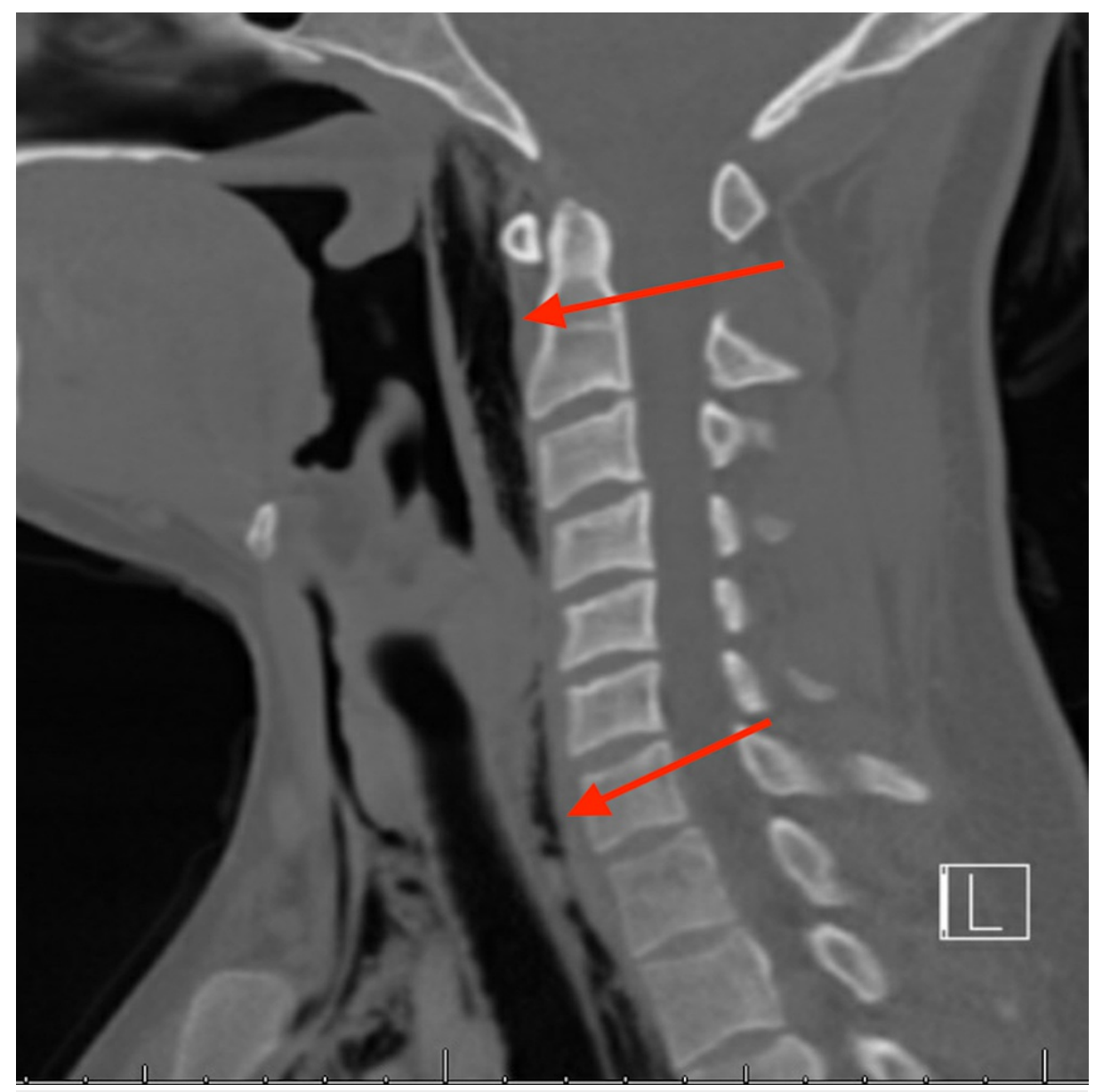

FIGURE 2: CT scan of the neck with intravenous contrast (sagittal section) showing gas tracking into the retropharyngeal space (red arrows)

L - left 


\section{Cureus}

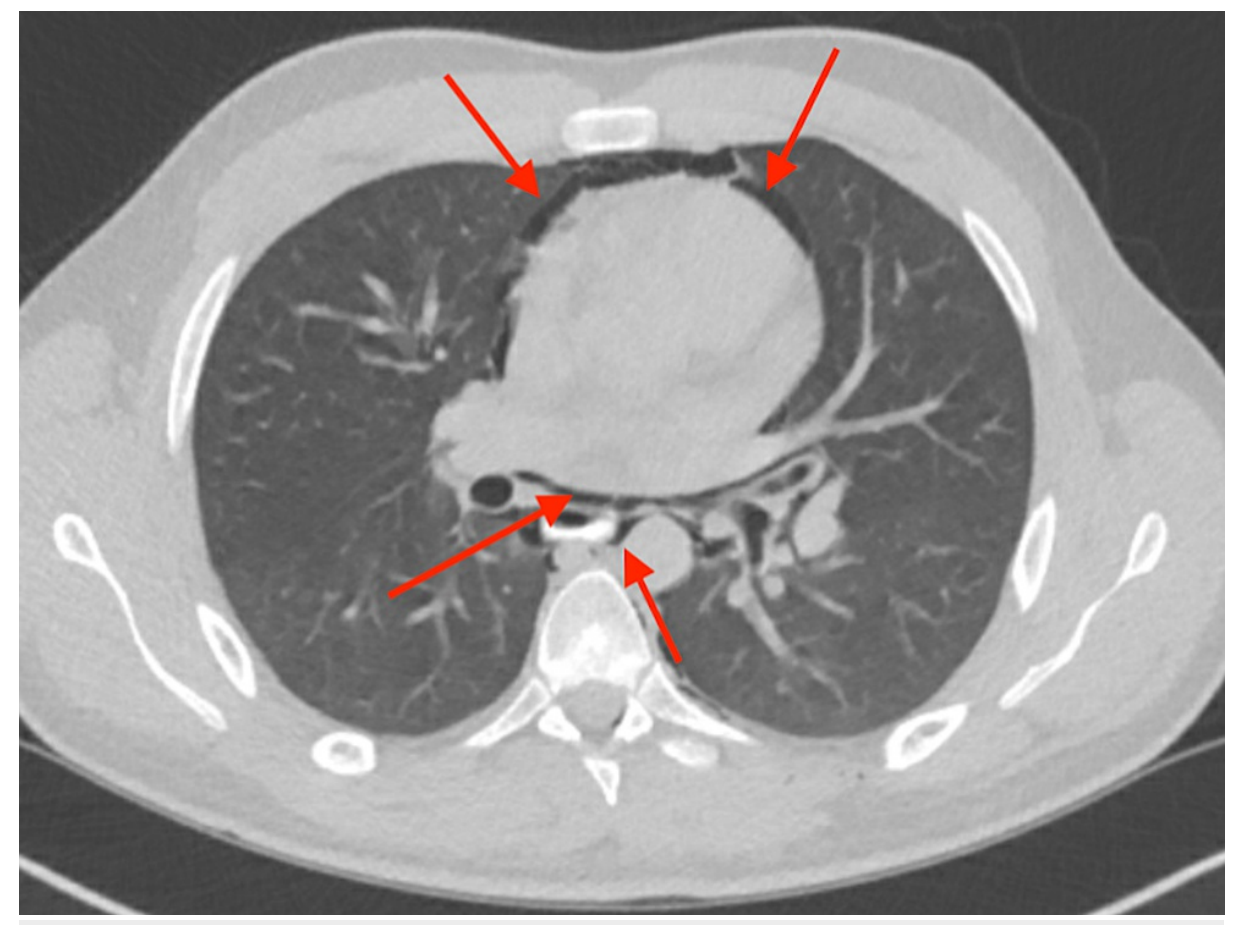

FIGURE 3: Axial CT scan showing curvilinear lucencies along mediastinal structures compatible with pneumomediastinum (red arrows)

The patient was admitted for monitoring and conservative management. The urine drug screen was positive for methamphetamine and cannabinoid. The otolaryngologist and gastroenterologist also evaluated the patient. Boerhaave's syndrome was ruled out and SPM was thought to be related to Ecstasy and marijuana use. Repeat serial chest imaging showed continued improvement in pneumomediastinum as well as decreasing gas within the overlying cervical soft tissues (Figure 4). 


\section{Cureus}

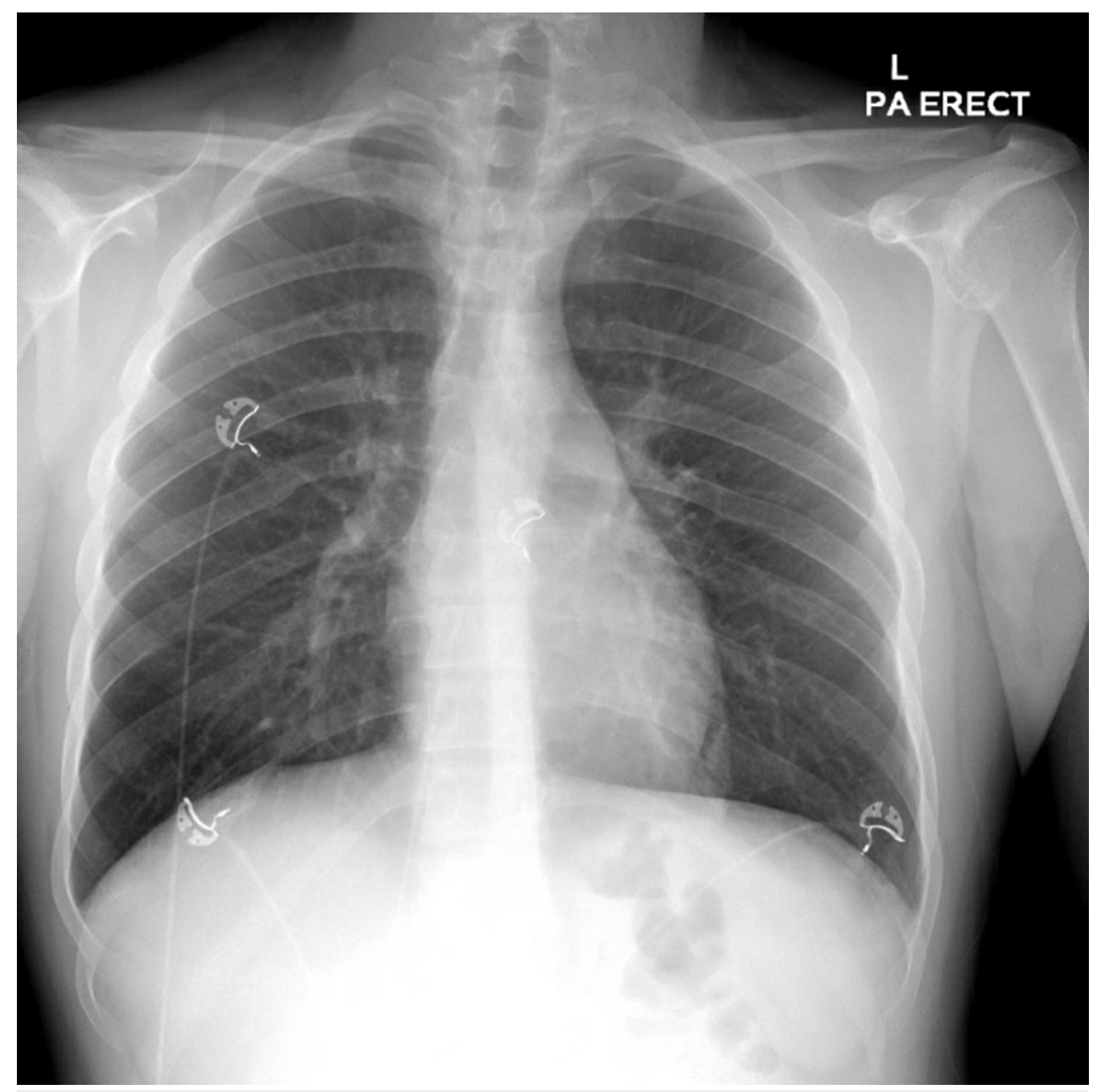

FIGURE 4: Chest x-ray showing improvement in pneumomediastinum and subcutaneous emphysema

L - left; PA - posteroanterior

The patient was discharged in stable condition on the fourth day of hospitalization.

\section{Discussion}

SPM and subcutaneous emphysema are more common phenomena after inhaled drugs than after ingested substances. Inhalation of drugs such as cocaine, marijuana, or Ecstasy followed by SPM, and subcutaneous emphysema can be explained by the barotrauma induced by the ritualistic Valsalva maneuver [11].

Inhalational use of marijuana has been associated with respiratory symptoms such as chronic cough, sputum production, dyspnea, and hoarseness [12], and has recently been described as a possible risk factor for chronic bullous lung disease and secondary pneumothorax [13]. A recent retrospective review revealed that SPM is associated with a history of inhaled marijuana use [7]. Although coughing is generally the most common precipitating factor for causing SPM, smoking techniques and marijuana-induced vomiting play a key role in causing SPM in marijuana users [7]. Moreover, vomiting was reported as the suspected mechanism of pneumomediastinum after Ecstasy ingestion [14,15]. In this case, the patient had two episodes of projectile vomiting after Ecstasy ingestion and marijuana inhalation, and immediately after the second episode of vomiting the patient developed neck and chest pain.

Patients with Ecstasy-related pneumomediastinum present with pleuritic chest pain with radiation to the neck [16] or back [17], neck swelling corresponding to underlying dysphonia [14], dysphagia [17], subcutaneous emphysema [18], and odynophagia [18]. The time of presentation varies as patients present several hours to days after the consumption of the substance. Most common examination findings include subcutaneous emphysema, tachycardia, and Hamman's sign [4]. In this case, the patient presented with complaints of neck and chest pain, and the symptoms developed approximately nine hours after ecstasy ingestion and marijuana inhalation. On initial examination, the patient was noted to have tachycardia, and there was crepitus over the neck and chest wall indicating subcutaneous emphysema. 
The recommended imaging modality in SPM is a chest radiograph [1]. Patients with pneumomediastinum or pneumopericardium should be arranged for an immediate contrast swallow to rule out esophageal rupture [18]. Pneumomediastinum is a benign and self-limiting condition. After excluding esophageal rupture, supportive management should be given with gradual reintroduction of fluids and food by mouth [15]. In this case, after initial evaluation, the patient had a chest x-ray, which revealed pneumomediastinum. Following the diagnosis of pneumomediastinum, esophagogram was performed and esophageal rupture was ruled out. The patient was then managed conservatively with gradual improvement of pneumomediastinum and subcutaneous emphysema.

\section{Conclusions}

SPM has been reported with both Ecstasy and marijuana use. History should be obtained regarding illicit drug abuse when dealing with pneumomediastinum especially in adolescent and young patients. Once the more fatal conditions of esophageal rupture and pneumothorax have been ruled out, Ecstasy and marijuanainduced SPM are managed conservatively with a self-limiting course.

\section{Additional Information \\ Disclosures}

Human subjects: Consent was obtained or waived by all participants in this study. Conflicts of interest: In compliance with the ICMJE uniform disclosure form, all authors declare the following: Payment/services info: All authors have declared that no financial support was received from any organization for the submitted work. Financial relationships: All authors have declared that they have no financial relationships at present or within the previous three years with any organizations that might have an interest in the submitted work. Other relationships: All authors have declared that there are no other relationships or activities that could appear to have influenced the submitted work.

\section{References}

1. Caceres M, Ali SZ, Braud R, Weiman D, Garrett HE Jr: Spontaneous pneumomediastinum: a comparative study and review of the literature. Ann Thorac Surg. 2008, 86:962-6. 10.1016/j.athoracsur.2008.04.067

2. Stull BW: Spontaneous pneumomediastinum following ecstasy ingestion and sexual intercourse . Emerg Med J. 2008, 25:113-4. 10.1136/emj.2006.041558

3. Önal Ö, Hasdıraz L, Oğuzkaya F: A rare cause of spontaneous pneumomediastinum: ecstasy ingestion . Turk Thorac J. 2015, 16:198-200. 10.5152/ttd.2015.4466

4. Gungadeen A, Moor J: Extensive subcutaneous emphysema and pneumomediastinum after ecstasy ingestion. Case Rep Otolaryngol. 2013, 2013:795867. 10.1155/2013/795867

5. Miller WE, Spiekerman RE, Hepper NG: Pneumomediastinum resulting from performing Valsalva maneuvers during marihuana smoking. Chest. 1972, 62:233-4. 10.1378/chest.62.2.233

6. Kouritas VK, Papagiannopoulos K, Lazaridis G, et al.: Pneumomediastinum. J Thorac Dis. 2015, 7:S44-9. 10.3978/j.issn.2072-1439.2015.01.11

7. Weiss ZF, Gore S, Foderaro A: Pneumomediastinum in marijuana users: a retrospective review of 14 cases . BMJ Open Respir Res. 2019, 6:e000391. 10.1136/bmjresp-2018-000391

8. Mutlu H, Silit E, Pekkafali Z, et al.: 'Ecstasy' (MDMA)-induced pneumomediastinum and epidural pneumatosis. Diagn Interv Radiol. 2005, 11:150-1.

9. Ricaurte GA, McCann UD: Recognition and management of complications of new recreational drug use . Lancet. 2005, 365:2137-45. 10.1016/S0140-6736(05)66737-2

10. Albanese J, Gross C, Azab M, Mahalean S, Makar R: Spontaneous pneumomediastinum: a rare complication of methamphetamine use. Respir Med Case Rep. 2017, 21:25-6. 10.1016/j.rmcr.2017.03.007

11. Seaman ME: Barotrauma related to inhalational drug abuse. J Emerg Med. 1990, 8:141-9. 10.1016/07364679(90)90223-I

12. Tetrault JM, Crothers K, Moore BA, Mehra R, Concato J, Fiellin DA: Effects of marijuana smoking on pulmonary function and respiratory complications: a systematic review. Arch Intern Med. 2007, 167:221-8. 10.1001/archinte.167.3.221

13. Fiorello A, Vicidomini G, Santini M: Marijuana smokers and lung bullae. Eur J Cardiothorac Surg. 2008, 34:706-7; author reply 707. 10.1016/j.ejcts.2008.06.033

14. Rezvani K, Kurbaan AS, Brenton D: Ecstasy induced pneumomediastinum. Thorax. 1996, 51:960-1. 10.1136/thx.51.9.960

15. Levine AJ, Drew S, Rees GM: 'Ecstasy' induced pneumomediastinum. J R Soc Med. 1993, 86:232-3.

16. Rejali D, Glen P, Odom N: Pneumomediastinum following Ecstasy (methylenedioxymetamphetamine, MDMA) ingestion in two people at the same 'rave'. J Laryngol Otol. 2002, 116:75-6. 10.1258/0022215021910230

17. Hutchison RP, Burgess B: Spontaneous pneumomediastinum--a right pain in the neck? . Injury. 2005, 36:801-3. 10.1016/j.injury.2004.12.032

18. Marasco SF, Lim HK: Ecstasy-associated pneumomediastinum. Ann R Coll Surg Engl. 2007, 89:389-93. $10.1308 / 003588407 X 183373$ 